\title{
RE-EMPHASIZING THE ROLES OF GENERAL MEDICAL AND DENTAL PRACTITIONERS REGARDING ORAL CANCER ERADICATION IN NIGERIA
}

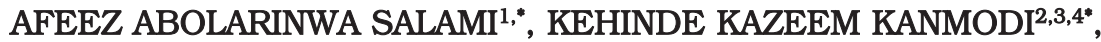 LAWRENCE ACHILLES NNYANZI ${ }^{2}$}

\author{
${ }^{1}$ Deparment of Oral and Maxillofacial Surgery, University College Hospital, Ibadan, Nigeria \\ ${ }^{2}$ School of Health and Life Sciences, Teesside University, Middlesbrough, UK \\ ${ }^{3}$ Medical Research Unit, Adonai Hospital, Karu, Nigeria \\ ${ }^{4}$ Campaign for Head and Neck Cancer Education (CHANCE) Programme, Cephas Health Research \\ Initiative Inc, Ibadan, Nigeria
}

\begin{abstract}
A b s t r a c t
The burden of oral cancer in Nigeria is largely under-reported. The available data on oral cancer etiology/risk factors, clinical features, disease burden, and literacy rate in Nigeria points towards a possible explosion in prevalence in the near future, which poses a serious public health concern. The general medical and dental practitioners (GMDPs) in Nigeria can salvage this looming problem through appropriate public health and clinical interventions. This narrative review article re-emphasizes the key roles of GMDPs towards oral cancer eradication in Nigeria. It also discusses oral cancer case definition, etiology, risk factors, and the epidemiological burden in the Nigerian context.
\end{abstract}

Keywords: Oral cancer, eradication, general, physicians, dentists, Nigeria

\section{KEY MESSAGES}

The burden of oral cancer disease and its risk factors in Nigeria is of a serious public health concern. The general medical and dental practitioners (GMDPs) in Nigeria can help salvage this looming problem through oral cancer education, screening, and prompt referrals.

\section{INTRODUCTION}

Oral cancer, in simple terms, is a group of malignancies that occur in the oral cavity and the oropharynx. Globally, oral cancer is the sixteenth commonest type of cancer and the fifteenth leading cause of cancer-related deaths worldwide. They are also the most common form of cancers affecting the head and neck region [1,2].

In both developing and developed nations, oral cancer is a disease of public health importance. Oral cancer has the lowest five-year survival rate among major cancers (including breast and colon cancers) with two-thirds of cases occurring in the developing nations majorly due to poverty, illiteracy, risky cultural beliefs, etc. [3]. Oral cancer occurs around the fifth decade of life and its occurrence is linked with some etiological/risk factors including tobacco and alcohol use, human papillomavirus (HPV) infections, background genetic susceptibility, environmental factors (such as excessive exposure to sunlight, industrial pollutions, etc.), poor nutritional states, amongst others [4].

Corresponding author: Dr. Kehinde Kanmodi, BDS, DFM, PGDE, PGDPSCR, PGDPM, ACIPM, CPMP, Cert (Mgt); e-mail: kanmodikehinde@yahoo.com

(C) 2021 Salami AA et al.

This work is licensed under the Creative Commons Attribution-NonCommercial-NoDerivs 4.0 License (https://creativecommons.org/licenses/by-nc-nd/4.0/) 
There is a persistently rising prevalence of oral cancer and its risk factors in Nigeria; however, only very little has been done towards oral cancer eradication in Nigeria, especially in the area of oral cancer education, screening, detection, and early management [5-12]. With the current rising trend of oral cancer risk factors in Nigeria, the need for routine oral cancer education, screening, detection, and early management cannot be overemphasized. In order to achieve an oral cancer-free status in Nigeria, so much effort needs to be invested towards these areas. The entire healthcare workforce in Nigeria has a collective role to play towards achieving an oral cancer-free status in Nigeria. However, for the scope of this study, we will limit our discussion to the roles of general medical and dental practitioners (GMDPs) towards the achievement of this desirable status.

Our study's scope is focused on the GMDPs because of our relatively deeper understanding of general medical and dental practice in Nigeria, compared to other clinical practice types. The GMDPs constitute a huge population of first-line givers of preventive oral and general healthcare services. Specifically, the primary jurisdiction of the general dental practitioners (GDPs) is the oro-facial region. Basically, oral health education and counseling, oro-facial examination, oro-facial disease detection, proper documentation, reporting and referral are routine procedures for GDPs. On the other hand, the conduct of general health education and counseling, general examination, systemic disease detection, proper documentation, reporting and referral are routine procedures for GMPs.

However, research has shown that most GMDPs in Nigeria have at least a basic knowledge of oral cancer (including its risk factors, common sites of occurrence, and clinical features) $[13,14]$. The GMDPs constitute the majority of the medical doctors and dentists in Nigeria. Also, the workforce size of GMDPs is bigger than that of the dental and medical specialists by far. Based on the afore-stated, the GMDPs basically have very huge roles to play when it comes to oral cancer eradication in Nigeria. However, in Nigeria, due to the very high patient-GMDP ratio in Nigeria, many GMDPs practicing in Nigeria are often overworked. The heavy burden of the clinical workloads on the heads of GMDPs in Nigeria often times limits their opportunity to deliver a very comprehensive healthcare service to their patients; this has resulted into GMDPs having inadequate time or poor attitude towards in-depth evaluation and education of their patients $[13,14]$. Unfortunately, this has invariably reduced patients' opportunity for holistic evaluation of their general and oral health status.

The need for proper evaluation and education of all patients by GMDPs on oral cancer cannot be overemphasized, more especially in Nigeria - a country with the rising burden of oral cancer risk factors. Hence, this study aims to give an overview about oral cancer case definition, its etiology, its risk factors, and as well the epidemiological burden in the Nigerian context. Importantly, this article aims to re-emphasize the highly crucial roles of GMDPs towards eradicating oral cancer in Nigeria.

\section{METHODS}

This study was a narrative review of relevant literature written on the topic of study. In our sourcing of literature, we used the following research databases: Google Scholar, PubMed, ResearchGate, SCOPUS, CINAHL, PsycINFO, and AJOL. Relevant information was retrieved from the literature obtained for this review.

\section{CASE DEFINITION AND ETIOLOGICAL / RISK FACTORS OF ORAL CANCER}

\section{Case Definition}

The majority of oral cancers are classified histologically as oral squamous cell carcinoma (OSCC); this is because most oral cancers develop from the squamous cells - a predominant cell group - in the oral cavity [15]. 
Early oral cancer lesions may go undetected due to the lack of symptoms and detectable signs and this contributes to the reasons for many late presentations by patients. Therefore, clinicians should look out for potential signs of oral cancers during routine oral examinations as they can easily be missed. These early oral cancer signs include alterations in the oral mucosa in the form of rough, red or red-white lesions, induration, fixation, non-healing extraction sockets, etc. [16] which may develop into a mass with associated ulcerations, lymph node enlargement, dysphagia, halitosis, bleeding, loss of appetite, and weight loss [17]. Thus, the examination of the oral cavity with thorough lymph node evaluation is of great importance.

\section{Etiological / Risk Factors}

The etiology of oral cancer is complex and can be described based on the various predisposing factors including tobacco use, alcohol use, exposure to human papillomavirus (HPV) through sexual activities, nutritional deficiency/poverty, industrial pollution, background genetic predisposition, sunlight exposure, etc. [19]. These risk factors vary based on ethnicity, race, environmental factors, cultural beliefs, socioeconomic factors (including access to health care, financial capacity, etc.), oral cancer knowledge, etc.

Tobacco Use: Tobacco use (either in smoked form [e.g. cigarette, cigar, pipe, etc.] or smokeless form [e.g. tobacco leaf, snuff, etc.]) alone is an oral cancer risk factor [19]. A mixture of tobacco with leaves and barks like kola nut, Areca nut (zupari), khat/miraa, toombak, betel quids, etc. are also oral cancer risk factors [20].

Many of the potential carcinogens in tobacco and their various products come in contact with the oral mucosa and permeate the oral tissues inducing a change in the deoxyribonucleic acid (DNA) of the cells thereby causing accumulation of damaged DNA in the cells. This damage in cellular DNA has been implicated in the pathogenesis of oral cancer [21] through the mutation of p53 gene, mutation of heterozygosity (H-RAS), and amplification of RAS oncogene leading to abnormal and uncontrollable cell division [22].

Kola Nut Consumption: The habitual chewing of kola nut has been described as an important risk factor for oral cancer especially in the Northwest and Northeast zones of Nigeria [23]. Kola nut chewing has been found to induce palatal keratinization and also have a cocarcinogenic potential when taken with tobacco [24]. It contains tannins that are capable of inducing oral cancer [24]. Ochratoxin A is also a toxic metabolite produced in kola nuts which is both carcinogenic and genetoxic [25].

Alcohol Consumption: Alcohol consumption plays a major role in the etiology of oral cancer. It works synergistically with tobacco to increase the risk of oral cancer by acting as a solvent to assist in the penetration of carcinogens in tobacco into the oral mucosal tissues. The additives in most alcoholic beverages as well as the metabolites of alcohol (acetaldehyde) also have direct carcinogenic effects by altering the p53 gene and RAS oncogene through the actions of the free radicals they generate [26,27]. Chronic alcohol consumption also reduces liver's ability to detoxify potential carcinogens thereby causing susceptibility to neoplasms including oral cancer [28].

Human Papillomavirus (HPV) Infection: Human papillomavirus (HPV) infections are primary initiators of cancer of the uterine cervix, anus, and the vagina, but a number of cases (about $50 \%$ ) of oral and oropharyngeal squamous cell carcinomas have been linked with HPV infections even though the causative mechanism is still unclear [29]. Reports suggest that functional dysregulation of the tumor suppressor genes (p53 and pRb) by the insertion of the viral DNA fragments (early genes E6 and E7, respectively) of carcinogenic HPV leads to uncontrolled DNA replication and an increased risk of neoplastic transformation. The 
HPV-16 and 18 subtypes have both been implicated in the pathogenesis of oral cancer with the HPV-18 subtype far less (14\%) commonly associated with it [30].

Nutritional Deficiency: Nutritional deficiency is a key predisposing factor to oral cancer [31]. Fruits and vegetables are foods rich in Vitamins A, C, and E - antioxidants. These antioxidants help to remove free radicals capable of causing cellular destruction [32]. Iron is also an essential micronutrient for the overall integrity of the epithelium of the digestive tract including the oral cavity which becomes atrophic during its deficiency [33]. A study reveals that despite the atrophic changes due to iron deficiency, there is an increased cell proliferation and epithelial turnover [34]. This proliferation can be linked to the etiology of cancer development. In fact, as far back as 1919, Paterson and Kelly have previously and independently linked nutritional deficiency with the development of cancer; they a described the Paterson-Kelly syndrome - a syndrome marked by iron deficiency, chronic anemia with different vitamin deficiencies [35,36]; also, this syndrome had been implicated in the development of pharyngeal and oral cancers [36,37].

Socioeconomic Status: There is no doubt that socioeconomic status has been linked with the prevalence of oral cancer worldwide even though some studies had yielded so many conflicting results [38]. Studies around the world and in Nigeria have revealed a decreased risk of oral cancers among individuals with high socioeconomic status based on increased level of education [38] and their occupation [39]. It is believed that those with high socioeconomic status have access to quality health care facilities and health awareness which are important in improving their health seeking behavior [40]; also, they undergo routine dental/oral checks which go a long way in facilitating early diagnosis of lesions including oral cancers $[41,42]$.

Cultural Beliefs: Poor cultural beliefs contribute to poor prognosis of oral cancers. Some people believe that cancer does not respond to orthodox treatments [43]; hence, they patronize traditional healers and herbalists who live within the local community. As a matter of fact, traditional healing is enshrined in the culture of the people, especially in Nigeria and many other climes. This makes hospitals therefore become a place of last resort where people with such cultural practice present at advanced stages of oral cancer leading to poor clinical outcomes and survival rate [43].

Genetic Factors: Few genetic factors are considered in the etiology of oral cancer. The alteration in the genetic makeup of cells either spontaneously or induced by mutagens has been linked with the tumogenesis of oral cancer [44]. Social factors like chewing of betel quids, smoking, actions of viruses, irradiations, or chemicals may lead to a segregation of chromosomes in the genes of cells. There may also be mutation of the H-RAS and K-RAS which are oncogenes leading to an upregulation of these oncogenic genes to predispose to oral squamous cell carcinoma - an oral cancer type $[44,45]$. This however shows the influence of the environmental factors on the genetic makeup.

Environmental Factors: Excessive exposure to sunlight through actinic radiation predisposes an individual to oral cancer (especially lip cancer) [46]. The repeated exposure to the ultraviolet rays in sunlight results in atrophy of the exposed aspect of the lower lip which can develop into oral cancer especially along the vermillion border of the lower lip. Hence, this explains the development of farmer's and sailor's lip [47].

Occupational Hazards: Occupational exposure to solvents like pesticides and other chemicals, engine exhausts, textile and leather dusts, etc. may increase the risk of oral cancers [48-52]. This claim is however conflicting; while some studies reported a link between oral cancer and various occupational exposures, some researchers had denied a relationship between them [48-52]. 
Age and Gender: Generally, oral cancer is associated with advancing age [53]. It is mainly diagnosed in persons who are older than 40 years [54]. However, some studies in Africa found a large proportion of oral cancer cases in persons who are below the age of 40 years $[55,56]$. Human papillomavirus had been implicated in cases of oral cancer amongst persons below the age of 40 years [57].

In Nigeria, the age of occurrence of oral cancer varies based on reports from different geopolitical zones in Nigeria and it ranges between the $3^{\text {rd }}$ and $6^{\text {th }}$ decades of life [58-60].

Oral cancer has also been reported to be commoner in males than females $(1.7: 1)$ but this ratio is getting closer and has narrowed to about 1.3:1 in recent studies [61,62]. Though the reason for the increase in incidence rate among females has not been fully understood; although an increase in the social habits like smoking and alcohol consumption among females have been suggested.

\section{CLINICAL FEATURES OF ORAL CANCER}

The diagnosis of oral cancer has been made as far back as the 2500-3000 BC when it was known as an eating ulcer of the gum as contained in Ebers Papyrus' work titled "Treaties on Tumours" [1]. Hence, oral cancer is a disease of the ancient times; unlike the popular belief which describes it as a disease of the modern era [1]. Proper clinical examination goes a long way in the accurate diagnosis of oral cancer. Accurate diagnosis of oral cancer requires an adequate understanding of the clinical features of the disease. There are numerous clinical features associated with oral cancer. Early oral cancer lesions are usually asymptomatic and are incidentally picked up while the advanced stages of the disease are usually symptomatic [63]. Oral cancers may present in a variety of forms, the appearance of all of which need to be familiar to the GMDPs for easy diagnosis.

Below are the clinical features associated with oral cancers, they are:

\section{Non-healing Oral Ulcer}

Oral ulcer is the loss or erosion of the delicate lining tissues of the oral cavity (i.e. the mucous membrane). They mostly respond to a regular therapy between 7 to 14 days [64]. However, an ulcer which persists for more than three weeks is one of the most frequent presentations for the early stage of oral cancer and should be biopsied $[65,66]$. Early lesions are usually painless and diagnosed through incidental finding. They appear as red or white lesions with indurated, rolled or ill-defined thickened margins with lack of surrounding inflammation in relation to the ulcer. The ulcers are mostly found in the tongue, floor of the mouth, gingivae mandibular alveolus, palate, etc. [67]. In fact, all unilateral/localized nonhealing ulcers should be examined and investigated for oral cancers [68].Dysplastic lesions on the lateral or ventral surface of the tongue as well as the floor of the mouth may however be suggestive of oral cancer [69]. Importantly, the advanced stage of oral cancer ulcer is associated with pain and it appears as large-sized solitary ulcer with raised borders and indurated margins with necrotic bases [70].

Oral cancer ulcers are persistent even following the exclusion of possible causes [63,64]. They are also non-responsive to any regular therapy and may rather increase in their intensity. GMDPs must clearly differentiate these suspicious lesions from normal reactive oral ulcerations [71].

\section{Dental Pain}

Oral cancer is often associated with pain especially at the advanced stage of the disease due to its induction of nerve dysfunction [64]. This mostly makes patient to present at the hospital as it affects their feeding, speech, swallowing, and general social interactions [72]. A tooth associated with oral cancer that is otherwise healthy with no evidence of pathology may become painful; this occurs in about $28 \%$ of oral cancer cases [73]. 


\section{Tooth Mobility}

Although tooth mobility may be caused by various factors like periodontitis, dental trauma, uncontrolled diabetes mellitus, etc.; it can also be seen in oral cancer patients. This may be associated with destruction of the supporting structures of the teeth (periodontium) by the tumour cells [74].

\section{Neck Mass (Lymph node enlargement)}

The potential of oral cancer cells to metastasize into the neighboring lymph nodes, especially the cervical lymph nodes has been well documented [75]. Hence, lymphedema is a common clinical finding in these patients [76].

\section{Progressive Swelling in the Mouth}

A progressively increasing oral swelling, a common oral cancer symptom, is due to the uncontrolled growth of the oral cancer tissues. These abnormal lumps progressively increase in size and could become ulcerated and erythematous due to a secondary trauma. This lesion may be fungating and exophytic with characteristic ulceration [77].

\section{Bleeding from the Oral Cavity}

Bleeding from the oral cavity in oral cancer patients may be due to the primary cancer or a secondary trauma on the abnormal oral cancer tissues [67].

\section{EPIDEMIOLOGICAL BURDEN OF ORAL CANCER AND ITS RISK FACTORS IN NIGERIA}

\section{Oral Cancer Data in Nigeria: Status Quo}

Oral cancer is one of the leading cancers among Africans, Nigerians inclusive [78]. However, due to inadequate and poorly functioning cancer registries, as well as under-reportage of oral cancer, the burden of oral cancer in Nigeria is still inaccurately depicted in official reports [78]. In fact, scientists have affirmed that the number of cases of oral cancer seen in Nigerian hospitals is far lesser than the number of people living with oral cancer [78]. Obviously, oral cancer disease burden is an issue that requires serious public health intervention.

\section{Prevalence of Oral Cancer in Nigeria}

The actual national prevalence of oral cancer In Nigeria is unknown; however, according to clinical epidemiological studies, about $1.2-2.7 \%$ of all malignant lesions are oral cancers $[79,80]$.

\section{Pattern of Oral Cancer in Nigeria}

Oral cancer lesion may involve the lip, tongue, floor of the mouth, retro-molar area, gingivae, buccal mucosa, palate, etc. The tongue and floor of the mouth are the most common sites of occurrence in the developed countries while studies in the developing nations have showed different sites of occurrence. In Nigeria, the maxillary antrum (14.2-36.7\%), mandibular alveolus (17.06-23\%), palate (12-16.5\%), tongue (5.2-12\%), had been recorded as the most common sites of the lesion while the floor of the mouth (4.7\%) and buccal mucosa (5.2\%) are the least common sites [18, 61, 81-83].

\section{Review of Oral Cancer Risk Factors in Nigeria}

A research had shown that tobacco users are three times more at risk of oral cancer than non-tobacco users [84]. This makes tobacco use in any form a significant risk factor for the development of oral cancer [85]. However, reports from Nigeria had only shown a low prevalence of tobacco use among Nigerian oral cancer patients. These reports favored poverty, nutritional deficiency, low socioeconomic status, chronic malaria, etc. as the significant predisposing factors to oral cancer among Nigerians [79]. This may anecdotally be linked with 
a withdrawal of sensitive social history such as tobacco and alcohol use by patients during hospital visits, as many of the patients who denied the use of tobacco may actually be consuming them or had just stopped consuming them.

The prevalence of HPV-induced oropharyngeal cancers is increasing in USA and across Europe (60\% and 31\%, respectively) with oral cancer recording just 3\%; this is strongly related to sexual habits and experience [86]. The risk of HPV-induced oral cancer increases with the number of sexual partners, increased oral/genital contacts, history of genital warts, and an early age of sexual debut [87]. However, in Nigeria, research into the HPV-induced oral cancer is quite limited. The cultural sensitivity among the people may have contributed to the difficulty in obtaining accurate data on the various sexual practices that could be linked with HPV-induced oral cancer. A multi-center study in Nigeria also showed that most oral cancer cases were HPV negative $[87,88]$. Hence, HPV may not be a significant predisposing factor for oral squamous cell carcinoma in Nigeria.

There is a common saying in Nigeria that kola nut is produced in the West by Yorubas, consumed in the North by Hausas, and worshipped in the East by the Igbos [89]. This underscores the fact that the northern region of Nigeria consume kola nut in a large quantity when compared to the other regions in Nigeria. The habitual chewing of kola nut has been described as an important risk factor for oral cancer especially in the northwestern and northeastern zones of Nigeria [23]. This suggests that the rate of kola nut-induced oral cancer will be higher in the northern parts of Nigeria than the Southern parts.

Poor cultural belief among some Nigerian population groups is also an oral cancer risk factor. For example, some people in the northern part of Nigeria believe that cancer does not respond to Orthodox treatment. Hence, they patronize traditional healers and herbalists (known as boka) who live within the community [43]. Similarly, in the southwestern part of Nigeria, many people believe that oral cancer is caused by various spiritual attacks [90]. Most patients however use herbal or spiritual remedies and only present at the hospital when the expected cure is not achieved. This leads to late presentations and also poor prognosis.

The northern part of Nigeria is said to be the hottest part of the country as mean monthly maximum temperature varies between 29 and 40 degree Celsius [91]. People in this part mainly engage in outdoor jobs like farming and are exposed to intense sunlight for several hours on a daily basis. This poses the risk of developing lower lip cancers which are three times more common in males than females [92]. Most of the men engage in outdoor occupation and majority of their wives take care of the children at home with little exposure to sunlight.

The prevalence of other oral cancer risk factors like tobacco use, alcohol drinking, and oral sex had been fairly studied in Nigeria. Nigerian studies had reported that at least one out of every ten to twenty Nigerians, particularly the young people, either smoke tobacco, drink alcohol, or engage in oral sex [93-95]. In times past, the prevalence rates of these behaviors were lower; however, due to ongoing Western civilizations, these rates have increased over the years [59,93-95]. This shows that oral cancer risk factors in Nigeria are issues of a serious public health concern

The above-described picture on the oral cancer risk factor burden predicts that Nigeria will most probably have an explosion in the rate of oral cancer prevalence in the future, if nothing is done towards curbing the prevalence of oral cancer etiological/risk factors among its populations.

\section{WHAT ARE THE ROLES OF GMDPS TOWARDS ORAL CANCER ERADICATION IN NIGERIA?}

The GMDPs have significant roles to play towards oral cancer eradication in Nigeria. These roles are multifaceted and they include both clinical and non-clinical interventions. Previous studies have shown that the GMDPs have basic knowledge of the risk factors, common sites of occurrence, and clinical features of oral cancer [13,14]; therefore, GMDPs are up to the task. 
Below are the roles of GMDPs regarding oral cancer eradication in Nigeria:

Public Enlightenment on the Major risk Factors and Clinical Features of Oral Cancer: Low public awareness of the risk factors of oral cancer as well as its presentations at its early stage have been identified as the factors contributing to late presentations and subsequent poor survival rate of oral cancer cases recorded in Nigeria [5-12]. Public awareness on oral cancer is highly important regarding its eradication in Nigeria. The ability of lay people to identify oral cancer risk factors and early symptoms will aid early and prompt clinical intervention.

Unfortunately, many health-related media-based information (especially those on social media) are misleading and encouraging behavior that make people prone to oral cancer [96]. The GMDPs can help promote proper public education on oral cancer through the use of community-based medical outreaches, patient education in clinics, print media, television and radio broadcasts, social media, etc. The adoption of this public health education strategy can bring about a change in the behavior and social lifestyle of people engaging in behavior that predisposes humans to oral cancer.

Early Detection and Diagnosis of Oral Cancer Lesions: It has been established that early diagnosis and treatment is associated with decreased mortality and better prognosis [64,72]. Routine screening for early lesions of oral cancer especially in the high-risk (i.e. those persons with oral cancer risk factors) have been shown to be highly beneficial. Routine oral cancer screening, either individual or population-based screening, has been found to significantly increase oral cancer prevention rate, improve treatment outcomes, and reduce mortality rate among oral cancer high risk groups in India [97]; therefore, there is high hope that the current oral cancer burden in Nigeria can be reduced to the barest minimum if GMDPs in Nigeria can intensify their engagements in community-based and clinic-based oral cancer screening programs.

Non-invasive diagnostic tools can be used by the GMDPs for early diagnosis of oral cancer lesions. The use of toluidine blue staining on suspicious oral mucosa changes is a good oral cancer diagnostic option which can be adopted by GMDPs in Nigeria. The technique is quite simple and less expensive for a low-resource setting like Nigeria. The technique is highly sensitive; however, less specific because of high false positive results [98]. Other non-invasive techniques like autofluorescence, chemiluminescence can also be used [99]. Biopsy of oral cancer lesions - the gold standard for the diagnosis of oral cancer - can also be done (especially by general dental practitioners).

Prompt Referral of newly Diagnosed Cases of Oral Cancer: Prompt referral by GMDPs to oral cancer specialist clinics following their diagnosis of oral cancer in general care patients is very important. Since oral cancer treatment outcome largely depends on the stage at which clinical intervention is done, then prompt treatment of the disease is non-negotiable $[7,78]$. Not all secondary healthcare facilities in Nigeria have equipment and specialists needed for oral cancer treatment. In fact, only very few healthcare centers in Nigeria have the capacity to treat oral cancer patients. Hence, all these facilities need to be known by GMDPs in Nigeria; also, prompt patient referrals should be made by GMDPs to these centers regarding newly detected oral cancer cases. By so-doing, the burden of oral cancer in Nigeria will reduce significantly.

Based on the above, we recommend that the stake holders involved in oral cancer eradication in Nigeria, under the leadership of the Federal Ministry of Health of Nigeria, should develop and produce a directory of medical centers and specialists responsible for advanced oral cancer care in Nigeria. Copies of this directory can be shared among GMDPs in Nigeria in order to ease their task in future referrals of oral cancer cases in Nigeria. 
Behavior Cessation Counseling: Some oral cancer risk factors, such as tobacco use, oral sex, and alcohol use are addictive behavior. These addictive behaviors can be difficult to quit without the help of clinical intervention. There are different clinical intervention strategies that can be adopted in the addictive behavior cessation treatment; however, the most effective of them is cessation counseling. However, behavior cessation counseling programs in Nigeria is not yet well-established unlike in the Western countries. In fact, based on the authors' experience, many hospitals in Nigeria do not have such programs in place for patients with addictions such as tobacco addiction, sex addiction, and alcohol addiction; this may be because quite a number of GMDPs in Nigeria lack adequate behavior cessation counseling knowledge and skills [100]. This shows that many GMDPs most probably need more training behavior cessation counseling.

Based on the above, it is highly recommended that all GMDPs in Nigeria receive adequately trained on behavior cessation counseling techniques. If the GMDPs acquire these skills, they will be placed in a stronger position to successfully assist their patients in quitting addictive behavior that can make them at risk of developing oral cancer disease.

Oral Cancer Prevention Advocacy: Advocacy on oral cancer prevention goes a very long way in the journey towards oral cancer eradication in Nigeria. The GMDPs are doctors; doctors are highly respected and influential persons in the Nigerian society. Importantly, the GMDPs form a large proportion of the population of doctors in Nigeria; hence, they have a very strong public voice when it comes to public health advocacy. Over the years, the GMDPs in Nigeria have successfully played very strong roles in many infectious disease eradication advocacy programs. However, only very little advocacy efforts had been channelled by GMDPs towards oral cancer eradication in Nigeria.

Oral cancer is a leading killer disease which appears to be neglected in Nigeria. Unfortunately, oral cancer is still yet to be widely seen as a public health threat in Nigeria. The GMDPS, having a strong voice in the Nigerian society, urgently need to put in more efforts towards oral cancer prevention advocacy in the country. Some of the policy areas that GMDPs can advocate for are "improvement in tobacco and alcohol regulation policies", "free oral cancer screening and diagnosis", "provision of free national HPV vaccination programs", "provision of free oral cancer care", and more. If the GMDPs can push for the implementation of progressive and workable public health policies in favor of oral cancer prevention (especially in those afore-mentioned policy areas), the burden of oral cancer in Nigeria will be brought to the barest minimum.

\section{CONCLUSION}

The burden of oral cancer in Nigeria is largely under-reported. However, the existing data on oral cancer disease burden, risk factors, and literacy rate in Nigeria still draws serious public health concerns, as these data are pointing towards possible explosion in oral cancer prevalence in the nearest future. The GMDPs in Nigeria can help salvage this looming problem through their public health and clinical interventions.

Author's contributions: Study conceptualization - AAS and KKK; study protocol design - AAS and KKK; manuscript drafting - AAS and KKK; review of drafted manuscript - LAN; acceptance of final version of manuscript - AAS, KKK and LAN. AAS and KK contributed equally to this study.

Funding:This study was self-funded.

Conflict of interest: Authors have none to declare. 


\section{REFERENCES}

1. Inchingolo F, Santacroce L, Ballini A, Topi S, Dipalma G, Haxhirexha K, Bottalico L, Charitos IA. Oral Cancer: A Historical Review. Int J Environ Res Public Health. 2020;17(9):3168.

2. Ren ZH, Hu CY, He HR, Li YJ, Lyu J. Global and regional burdens of oral cancer from 1990 to 2017: Results from the global burden of disease study. Cancer Commun (Lond). 2020;40(2-3):81-92.

3. Adebola RA, Bamgbose BO, Adeoye JB, Amole TG. Research article: Awareness of oral cancer in a northwestern Nigerian state: assessing the knowledge, opinion and practice of traditional healers and herbalists. J Oral Oncol 2013:263150.

4. Okoh M, Okoh DS. Oral cancer-The Nigerian perspective. J Mol Biomark Diagn 2017;8:369.

5. Kanmodi KK, Kanmodi PA. Rising prevalence of head and neck cancer risk factors among Nigerian adolescents: A call for school-based intervention programmes. Popul Med 2020;2(May):13.

6. Kanmodi KK, Fagbule OF. Towards head and neck cancer prevention in Nigeria: Insights from the CHANCE programme. Popul Med 2020;2(June):16.

7. da Lilly-Tariah OB, Somefun AO, Adeyemo WL. Current evidence on the burden of head and neck cancers in Nigeria. Head Neck Oncol. 2009;1:14.

8. Otoh EC, Johnson NW, Danfillo IS, et al. Primary head and neck cancers in North Eastern Nigeria. West Afr J Med. 2004;23(4):305-13.

9. Somefun OA, Nwawolo CC, Okeowo PA, et al. Prognostic factors in the management outcome of carcinoma of the larynx in Lagos. Niger Postgrad Med J. 2003;10(2):103-6.

10. Sowemimo GO, Ademiluyi SA, Oyeneyin JO. Salivary gland tumours. Niger Med J. 1978;8(2):11923.

11. Ketiku KK, Igbinoba F, Okeowo PA. Nasopharyngeal cancer in Nigeria - A revisit. Niger Postgrad Med J. 1998;5:7-11.

12. Lilly-Tariah da OB, Somefun OA. Outcome of total laryngectomy in the treatment of cancer of the larynx in the middle belt plateau of Nigeria. Nig J Surg. 2002;8:35-38.

13. Gbotolorun OM, Ayodele ASO, Oojede ACO, Adamson OO, Emeka CI, Amoo AT. Knowledge and screening practices for oral cancers amongst general dental practitioners in Lagos, Nigeria. Afr J Biomed Res 2014;17: 69-73.

14. Gbotolorun OM, Eweka O, Lawal A, et al. Knowledge, opinions, and practices about oral cancer among general medical practitioners in Lagos, Nigeria. J Oral Res Rev 2015;7(1):6-11.

15. Rivera C. Review article: Essentials of oral cancer: Int J Clin Exp Pathol 2015;8(9):11884-11894.

16. Baykul T, Yilmaz HH, Aydin U, Aydin MA, Aksoy M, Yildirim D. Early diagnosis of oral cancer. J Int Med Res. 2010 May-Jun;38(3):737-49.

17. Bagan J, Sarrion G, Jimenez Y. Oral cancer: clinical features. Oral Oncol. 2010;46(6):414-7.

18. Arotiba JT, Obiechina AE, Fasola OA, Fawole OI, Ajagbe HA. Oral squamous cell carcinoma: a review of 246 Nigerian cases. Afr J Med Med Sci. 1999;28(3-4):141-4.

19. Conway DI, Purkayastha M, Chestnutt IG. The changing epidemiology of oral cancer: definitions, trends, and risk factors. Br Dent J. 2018;225(9):867-873.

20. Hille J, Johnson NW. The burden of oral cancer in sub-Saharan Africa: An estimate as presented to the Global Oral Cancer Forum, 2016. Trans Res Oral Oncol 2017;2:1-13.

21. Nylander K, Dabelsteen E, Hall PA. The p53 molecule and its prognostic role in squamous cell carcinomas of the head and neck. J Oral Pathol Med. 2000;29(9):413-25.

22. Scully C, Bedi R. Ethnicity and oral cancer. Lancet Oncol. 2000;1(1):37-42.

23. Otoh EC, Johnson NW, Mandong BM, et al. Pattern of oral cancers in the North Central zone of Nigeria. Afr J Oral Health 2004;1(1):47-53.

24. Odukoya O, Roberts T, Aroll G. A cytologic study of the effect of Kolanut on the keratinization of the palatal mucosal of Nigerian smokers. Afr Dent J. 1990;4(1-5):1-5.

25. Dongo LN, Manjula K, Orisajo SB. Occurrence of Ochratoxin A in Kolanuts. Annual report of Cocoa Research Institute of Nigeria. 2007;28.

26. Harty LC, Caporaso NE, Hayes RB, Winn DM, Bravo-Otero E, Blot WJ, Kleinman DV, Brown LM, Armenian HK, Fraumeni JF Jr, Shields PG. Alcohol dehydrogenase 3 genotype and risk of oral cavity and pharyngeal cancers. J Natl Cancer Inst. 1997;89(22):1698-705. 
27. Rudolf P, Ayvis K. Ulcerative conditions. In: Regezi J, Scuibba J, Jordan R (Eds). Oral pathology clinical pathologic corrections. Saunders, Missouri, 2003. p 52-55.

28. Reidy J, McHugh E, Stassen LF. A review of the relationship between alcohol and oral cancer. Surgeon. 2011;9(5):278-83.

29. Clifford GM, Smith JS, Plummer M, Muñoz N, Franceschi S. Human papillomavirus types in invasive cervical cancer worldwide: a meta-analysis. Br J Cancer. 2003;88(1):63-73.

30. Reddout N, Christensen T, Bunnell A, Jensen D, Johnson D, O'Malley S, Kingsley K. High risk HPV types 18 and 16 are potent modulators of oral squamous cell carcinoma phenotypes in vitro. Infect Agent Cancer. 2007;2:21.

31. Kujan O, Farah CS, Johnson NW. Oral and oropharyngeal cancer in the Middle East and North Africa: Incidence, Mortality. Trends and gaps in public databases as presented to the Global Oral Cancer Forum. Trans Res Oral Oncol 2017;2:1-9.

32. Winn DM. Diet and nutrition in the etiology of oral cancer. Am J Clin Nutr. 1995;61(2):437S-445S.

33. Lippman SM, Benner SE, Hong WK. Cancer chemoprevention. J Clin Oncol. 1994;12(4):851-73.

34. Rennie JS, MacDonald DG, Dagg JH. Quantitative analysis of human buccal epithelium in iron deficiency anaemia. J Oral Pathol. 1982;11(1):39-46.

35. Rennie JS, MacDonald DG. Quantitative histological analysis of the epithelium of the ventral surface of hamster tongue in experimental iron deficiency. Arch Oral Biol. 1982;27(5):393-7.

36. Paterson DR. A Clinical Type of Dysphagia. Proc R Soc Med. 1919;12(Laryngol Sect):235-9.

37. Ahlbom HE. Simple achlorhydric anaemia, Plummer-Vinson syndrome, and carcinoma of the mouth, pharynx, and oesophagus in women: Observations at Radiumhemmet, Stockholm. Br Med J. 1936;2(3945):331-3.

38. Hashibe M, Jacob BJ, Thomas G, Ramadas K, Mathew B, Sankaranarayanan R, Zhang ZF. Socioeconomic status, lifestyle factors and oral premalignant lesions. Oral Oncol. 2003;39(7):66471.

39. Ferraroni M, Negri E, La Vecchia C, D’Avanzo B, Franceschi S. Socioeconomic indicators, tobacco and alcohol in the aetiology of digestive tract neoplasms. Int J Epidemiol, 1989;18(3):556-562.

40. Elwood JM, Pearson JC, Skippen DH, Jackson SM. Alcohol, Smoking, social, and occupational factors in the aetiology of cancer of the oral cavity, pharynx and larynx. Int J Cancer 1984;34(5):603612 .

41. Johnson S, McDonald JT, Corsten M, Rourke R. Socio-economic status and head and neck cancer incidence in Canada: a case-control study. Oral Oncol. 2010;46(3):200-3.

42. Petersen PE. Oral cancer prevention and control--the approach of the World Health Organization. Oral Oncol. 2009;45(4-5):454-60.

43. Adeola DS, Obiadazie AC. Oro-facial carcinoma in Kaduna. Nigerian Journal of Surgical Research. 2006; 8(3-4):144-147

44. Patel BP, Trivedi PJ, Brahmbhatt MM, Shukla SN, Shah PM, Bakshi SR. Mutagen sensitivity in oral cancer patients, healthy tobacco chewers and controls. Acta Cytol. 2010;54(2):169-74.

45. Saranath D, Chang SE, Bhoite LT, Panchal RG, Kerr IB, Mehta AR, Johnson NW, Deo MG. High frequency mutation in codons 12 and 61 of $\mathrm{H}$-ras oncogene in chewing tobacco-related human oral carcinoma in India. Br J Cancer. 1991;63(4):573-8.

46. Johnson NW. Detection of patients and lesions at risk. Oral cancer 1991;2:47-9

47. Matsuda H, Konishi N, Hiasa Y, Hayashi I, Tsuzuki T, Tao M, Kitahori Y, Yoshioka N, Kirita T, Sugimura M. Alterations of p16/CDKN2, p53 and ras genes in oral squamous cell carcinomas and premalignant lesions. J Oral Pathol Med. 1996;25(5):232-8.

48. Osterkamp RW, Whitten JB. The etiology and pathogenesis of oral cancer. CA Cancer J Clin. 1973;23(1):28-32.

49. Kvam BM, Romundstad PR, Boffetta P, Andersen A. Cancer in the Norwegian printing industry. Scand J Work Environ Health. 2005;31(1):36-43.

50. Schildt EB, Eriksson M, Hardell L, Magnuson A. Occupational exposures as risk factors for oral cancer evaluated in a Swedish case-control study. Oncol Rep. 1999;6(2):317-20.

51. Winn DM, Blot WJ, Shy CM, Fraumeni JF Jr. Occupation and oral cancer among women in the South. Am J Ind Med. 1982;3(2):161-7. 
52. Brasil VLM, Ramos Pinto MB, Bonan RF, Kowalski LP, da Cruz Perez DE. Pesticides as risk factors for head and neck cancer: A review. J Oral Pathol Med. 2018;47(7):641-651.

53. Enwonwu CO, Meeks VI. Bionutrition and oral cancer in humans. Crit Rev Oral Biol Med. 1995;6(1):5-17.

54. Johnson NW. Orofacial neoplasms: global epidemiology, risk factors and recommendations for research. Int Dent J. 1991;41(6):365-75.

55. Ajayi OF, Adeyemo WL, Ladeinde AL, Ogunlewe MO, Effiom OA, Omitola OG, Arotiba GT. Primary malignant neoplasms of orofacial origin: a retrospective review of 256 cases in a Nigerian tertiary hospital. Int J Oral Maxillofac Surg. 2007;36(5):403-8.

56. Chidzonga MM. Oral malignant neoplasia: a survey of 428 cases in two Zimbabwean hospitals. Oral Oncol. 2006;42(2):177-83.

57. Menezes FDS, Latorre MDRDO, Conceição GMS, Curado MP, Antunes JLF, Toporcov TN. The emerging risk of oropharyngeal and oral cavity cancer in HPV-related subsites in young people in Brazil. PLoS One. 2020;15(5):e0232871.

58. Ajayi OO. Cancer in Africa. Proceedings of a workshop of the West African College of physicians Ed. Olatunbosun DA. 1981 pp 168-169.

59. Owor R. Cancer as seen in east Africa. In: Olatunbosun DA, editor. Cancer in Africa Proceedings of a workshop of the West African College of Physicians. 1981; pp 33-49.

60. Effiom OA, Adeyemo WL, Omitola OG, Ajayi OF, Emmanuel MM, Gbotolorun OM. Oral squamous cell carcinoma: a clinicopathologic review of 233 cases in Lagos, Nigeria. J Oral Maxillofac Surg. 2008;66(8):1595-9.

61. Arotiba GT, Ladeinde AL, Oyeneyin JO, Nwawolo CC, Banjo AA, Ajayi OF. Malignant orofacial neoplasms in Lagos, Nigeria. East Afr Med J. 2006 Mar;83(3):62-8.

62. Olusanya AA, Adisa AO, Aladelusi TO, Lawal OA, Adeyemi BF, Gbolahan OO, et al. Orofacial cancers: pattern and management in Ibadan, Nigeria. Med J Zambia. 2018; 45(4):179-188.

63. Scully C, Bagan J. Oral squamous cell carcinoma: overview of current understanding of aetiopathogenesis and clinical implications. Oral Dis. 2009;15(6):388-99.

64. Huber MA. A review of premalignant oral conditions. Tex Dent J. 2006;123(6):502-9.

65. Bagan J, Sarrion G, Jimenez Y. Oral cancer: clinical features. Oral Oncol. 2010;46(6):414-7.

66. Sloan P. Squamous cell carcinoma and precursor lesions: clinical presentation. Periodontol 2000. 2011;57(1):10-8.

67. Sharma RG, Bang B, Verma H, Mehta JM. Profile of oral squamous cell cancer in tertiary level medical college Hospital: 10-year study. Indian J Surg Oncol. 2012;3(3):250-4.

68. Awadallah M, Idle M, Patel K, Kademani D. Management update of potentially premalignant oral epithelial lesions. Oral Surg Oral Med Oral Pathol Oral Radiol. 2018;125(6):628-636.

69. Porter S, Gueiros LA, Leão JC, Fedele S. Risk factors and etiopathogenesis of potentially premalignant oral epithelial lesions. Oral Surg Oral Med Oral Pathol Oral Radiol. 2018;125(6):603-611.

70. Van Zyl AW, Bunn BK. Clinical features of oral cancer. South African Dental Journal. 2012;67(10): 566-569.

71. Yang SW, Lee YS, Chang LC, Hwang CC, Chen TA. Use of endoscopy with narrow-band imaging system in detecting squamous cell carcinoma in oral chronic non-healing ulcers. Clin Oral Investig. 2014;18(3):949-59.

72. Dios PD, Lestón JS. Oral cancer pain. Oral Oncol. 2010;46(6):448-51.

73. Stavrianos SD, Camilleri IG, McLean NR, Piggot TA, Kelly CG, Soames JV. Malignant tumours of the maxillary complex: an 18-year review. Br J Plast Surg. 1998;51(8):584-8.

74. Kim OS, Uhm SW, Kim SC, Lee BA, Kim OJ, Kim YJ et al. A case of squamous cell carcinoma presenting as localized severe periodontitis in maxillary gingiva. L Periodontal. 2012;83(6):753-6.

75. Kohler H, Kowalski L. Prognostic impact of level of neck metastasis in oral cancer patients. Braz J Otorhinolaryngology. 2012;78(6):15-20.

76. Adeyemi BF, Kolude B. Clinical presentation of oral squamous cell carcinoma. Niger Postgrad Med J. 2013;20(2):108-10.

77. Li Q, Wu D, Liu WW, Li H, Liao WG, Zhang XR, Liu ZM, Guo ZM, Liu XK. Survival impact of cervical metastasis in squamous cell carcinoma of hard palate. Oral Surg Oral Med Oral Pathol Oral Radiol. 2013;116(1):23-7. 
78. Omitola OG, Soyele OO, Sigbeku O, Okoh D, Akinshipo AO, Butali A, Adeola HA. A multi-centre evaluation of oral cancer in Southern and Western Nigeria: an African oral pathology research consortium initiative. Pan Afr Med J. 2017;28:64.

79. Oji C, Chukwuneke FN. Oral cancer in Enugu, Nigeria, 1998-2003. Br J Oral Maxillofac Surg. 2007;45(4):298-301.

80. Arotiba JT, Obiechina AE, Fasola OA, Fawole OI, Ajagbe HA. Oral squamous cell carcinoma: a review of 246 Nigerian cases. Afr J Med Med Sci. 1999;28(3-4):141-4.

81. Bhatia PL. Head and neck cancer in Plateau state of Nigeria. West Afr J Med. 1990;9(4):304-10.

82. Edington GM, Maclean CM. A cancer rate survey in Ibadan, Western Nigeria, 1960-63. Br J Cancer. 1965;19(3):470-81.

83. Olege FE, Adeniyi K.A, Segun-Busari S. Clinico pathological study of head and neck cancers in Ilorin, Nigeria Trop Doct 2005;35(1):2-4.

84. Gandini S, Botteri E, Iodice S, Boniol M, Lowenfels AB, Maisonneuve P, Boyle P. Tobacco smoking and cancer: a meta-analysis. Int J Cancer. 2008;122(1):155-64.

85. Lawal AO, Kolude B, Adeyemi BF. Oral cancer: The Nigerian experience. Int J Med Med Sci 2013;5(4):178-183.

86. Gillison ML, Chaturvedi AK, Anderson WF, Fakhry C. Epidemiology of Human PapillomavirusPositive Head and Neck Squamous Cell Carcinoma. J Clin Oncol. 2015;33(29):3235-42.

87. Hennessey PT, Westra WH, Califano JA. Human papillomavirus and head and neck squamous cell carcinoma: recent evidence and clinical implications. J Dent Res. 2009;88(4):300-6.

88. Kreimer AR, Clifford GM, Boyle P, Franceschi S. Human papillomavirus types in head and neck squamous cell carcinomas worldwide: a systematic review. Cancer Epidemiol Biomarkers Prev. 2005; 14(2):467-75.

89. Asogwa EU, Otuonye AH, Mokwunye FC, Oluyole KA, Ndubuaku TCN, Uwagboe EO. Kolanut production, processing and marketing in the South-Eastern states in Nigeria. Afr J Plant Sci. 2012; 5(10):547-551.

90. Asuzu CC, Akin-Odanye EO, Asuzu MC, Holland J. A socio-cultural study of traditional healers role in African health care. Infect Agent Cancer. 2019;14:15. doi: 10.1186/s13027-019-0232-y.

91. Buba LF, Ibrahim AM. Temperature variations as evidence of climate change in Northern Nigeria. Bayero J Pure Appl Sci. 2017;10(2):99-106.

92. Perea-Milla López E, Miñarro-Del Moral RM, Martínez-García C, Zanetti R, Rosso S, Serrano S, Aneiros JF, Jimenez-Puente A, Redondo M. Lifestyles, environmental and phenotypic factors associated with lip cancer: a case-control study in southern Spain. Br J Cancer. 2003;88(11):1702-7.

93. Adeloye D, Auta A, Fawibe A, Gadanya M, Ezeigwe N, Mpazanje RG, Dewan MT, Omoyele C, Alemu W, Harhay MO, Adewole IF. Current prevalence pattern of tobacco smoking in Nigeria: a systematic review and meta-analysis. BMC Public Health. 2019;19(1):1719.

94. Ajayi AI, Owolabi EO, Olajire OO. Alcohol use among Nigerian university students: prevalence, correlates and frequency of use. BMC Public Health. 2019;19(1):752.

95. Kanmodi K, Fagbule O, Ogunniyi K, Ogbeide M, Samuel V, Aliemeke E, Olatunji Y, Isola T, Adewuyi H, Musa S. Determinants of sexual practices among secondary school students in Nigeria: Focusing on socio-cultural and school-related factors. Rwanda Med J 2020;77(4):32-37.

96. Kanmodi KK, Adegbile OE, Ogidan IO, Kanmodi PA. What are we learning on social media about shisha? A case study of top 50 short English YouTube shisha videos. Yen Med J 2020;2(4):38-47.

97. Coelho KR. Challenges of the oral cancer burden in India. J Cancer Epidemiol. 2012;2012:701932.

98. Patton LL, Epstein JB, Kerr AR. Adjunctive techniques for oral cancer examination and lesion diagnosis: a systematic review of the literature. J Am Dent Assoc 2008;139(7):896-905.

99. Messadi DV. Diagnostic aids for detection of oral precancerous conditions. Int J Oral Sci. 2013 Jun;5(2):59-65.

100. Kanmodi KK. Dentists' role in clinical tobacco cessation interventions: The status in Nigeria. Popul Med 2020;2(November):37.

Received: July 17, 2021

Accepted: November, 11, 2021 